\begin{tabular}{l} 
Journal of Economics and Behavioral Studies (ISSN: 2220-6140) \\
Vol. 10, No. 5, pp. 73-88, October 2018 \\
\hline \hline
\end{tabular}

\title{
Behavioral and Environmental Influences on Entrepreneurial Orientation
}

\author{
Jeff Y-J Chen ${ }^{1}$, Boris Urban² \\ ${ }^{1}$ The University of Pretoria's Gordon Institute of Business Science, Johannesburg, South Africa \\ 2University of the Witwatersrand, Park Town, Johannesburg, South Africa \\ chenj@gibs.co.za, boris.urban@wits.ac.za
}

\begin{abstract}
Traditionally, theories of innovation and entrepreneurship have concentrated on either environmental or dispositional variables to explain different rates and levels in entrepreneurial activity. However, these theories have unsuccessfully represented the complexity of human behavior actions involve the interaction of various environmental, cognitive, and behavioral variables. Recognizing this shortcoming and considering that contextual influences on entrepreneurial behavior in an emerging market context are rarely accounted for, this study empirically examined the degree to which individual-level variables of entrepreneurial alertness and self-efficacy interact with environmental dynamism and hostility to influence a firm's entrepreneurial orientation. Appreciating the multiplicity of elements facing an entrepreneur who is trying to make sense of the external environment, the study surveyed 310 owner-mangers in South Africa and relied on SEM to determine the best model fit. The study findings reveal that as a result of mediating and interaction effects, an individual with higher levels of alertness and self-efficacy is more likely to be innovative, engage in risk-taking behavior and show pro-activeness, in other words, have higher levels of entrepreneurial orientation. It is recommended that policymakers encourage entrepreneurial orientation by fostering a high-support route in which the effects of the hostile environments are minimized to encourage higher levels of innovation. Moreover, scholars can build on these findings by investigating the interconnectedness of exogenous environmental and individual factors in terms of explaining entrepreneurial orientation.
\end{abstract}

Keywords: Innovation, entrepreneurial alertness, entrepreneurial self-efficacy, environmental dynamism and hostility, entrepreneurial orientation, South Africa.

\section{Introduction}

Scholars increasingly recognize that innovation is a multi-faceted construct which integrates the behaviors of individuals; organizational and environmental factors (Anderson et al., 2009; Poon, 2006; Rauch et al., 2009; Urban, 2007). Furthermore, research finds that not only are entrepreneurship and innovation corresponding, but an amalgamation of the two is vital towards achieving sustainability in today's dynamic and everchanging environment (Dess and Lumpkin, 2005). Entrepreneurship is highly relevant to economic development, poverty alleviation, wealth generation, job creation and spurs the economic growth of many developed and developing or emerging countries (Samson \& Mahmood, 2015). However, despite much promise many Small and Medium Enterprises (SMEs) in developing countries have not delivered on their potential (Lundström \& Stevenson, 2005; Urban, 2016). One reason for such failure is that while the external environment's influence on SMEs has been the subject of much debate (Davidsson et al., 2006; Dobbs \& Hamilton, 2007), the importance of an individual's orientation, as a crucial feature to business performance is often neglected (Estrin et al., 2013; Piispanen et al., 2018).

As a consequence, the process of innovation and entrepreneurship cannot be viewed in isolation but rather as a set of interrelated factors, where the multitude of factors involved in improving or restraining entrepreneurship needs to give sufficient attention (Urban, 2007). The objectives of this study are to empirically examine the extent to which the individual level variables of entrepreneurial alertness and selfefficacy interact with environmental dynamism and hostility to influence the entrepreneurial orientation of SMEs in South Africa. In South Africa, entrepreneurship is viewed as crucial for economic development, yet low levels of total entrepreneurial activity (TEA) rate persist, causing South Africa to be among the lowermost in their peer group of developing nations (Herrington et al. 2017). Recognizing this shortcoming and considering the neglect of studying contextual and individual influences on entrepreneurial behavior (Haynie 
et al. 2010; Shane and Venkataraman, 2000), this study adds to the business literature by emphasizing the importance of the environment and seeks to explain how successful entrepreneurial ventures 'fit' best with their environments (Luthans et al., 2000; Welter and Small bone 2011).

Accounting for the multiplicity of such elements illustrates the challenges facing entrepreneurs who are trying to make sense of the external environment in an emerging economy (Urban \& Hwindingwi, 2016). The importance of the study is evident when considering environmental influences are imperative to entrepreneurs who need to formulate strategies based on reliable information to recognize and exploit opportunities, while at the same time manage risk and deal with uncertainty (Bamiatzi \& Kirchmaier, 2012; Urban \& Hwindingwi, 2016). Theoretical frameworks and models suggest that context is an essential determinant of entrepreneurial success as the specific attributes within each context influence the success or failure of the business (Moroz \& Hindle, 2012). External environmental factors may be determined in terms of 'environmental munificence' (i.e. favorable environmental conditions) or 'hostility' (i.e. unfavorable environmental conditions), both of which offer opportunities as well as challenges which enterprises need to respond to in entrepreneurial and innovative ways (Brownhilder, 2016; Hameed \& Ali, 2011). Moreover, research findings show that SMEs are vulnerable since they are new and small, and hence environmental forces may have a greater impact on their operations. Additionally, the ability of entrepreneurs to remain alert to opportunities and be confident in their capabilities, while surveying their uncertain environments is pivotal for successfully high performing businesses (Bruwer, 2018).

Research findings emphasize that successful entrepreneurs seem to excel at discovering opportunities entrenched in the environment which they scan, as their alertness allows them to spot high pay-off opportunities (Baron, 2006; Gaglio and Katz 2001). This suggests that an entrepreneurial mindset impacts decision making (Haynie et al., 2010), where one's cognitive adaptability in terms of alertness, flexibility, and self-regulation, under dynamic and uncertain environments is important (McGrath \& Macmillan, 1992). Cognition has been described as the mental processing which individuals rely on to deal with their environments (Baron, 2006). Consequently, levels of entrepreneurial alertness and self-efficacy can vary depending on the person's context. Several researchers have used the entrepreneurial self-efficacy (ESE) construct to study entrepreneurial behavior, as it refers to the "strengths of a person's belief that he/she is capable of successfully performing the various roles and tasks of an entrepreneur" (Bandura, 1986; Chen et al., 1998; De Noble et al., 1999). There is a growing stream of literature which suggests that higher levels of ESE affect entrepreneurial intentions and subsequent action, leading to calls for future research to interrogate ESE so as to understand casual directions between ESE and related variables, as well as to determine how ESE is associated to innovation (McGee et al., 2009). Nonetheless and despite their potential, entrepreneurial alertness and ESE remain understudied in African and emerging market contexts (Urban, 2016).

This is somewhat limiting considering the importance of understanding their potential interplay within a dynamic and often hostile environmental context (Busenitz et al., 2014; Kaish and Gilad 1991). Prior studies on the contextual landscape in Africa indicate that SMEs need to affiliate their business strategies with fitting entrepreneurial orientations to alleviate some of the negative results of functioning in such hostile environments (Brownhilder, 2016). Following the work of Khanna and Palepu (2010), under ideal market conditions every country would off era range of functioning institutions to support businesses in developing or emerging markets but in reality in emerging economies institutions are not sufficiently robust to allow buyers and sellers to transact easily. Such 'institutional voids' pose many challenges for businesses in emerging markets when compared to businesses in developed economies with well-defined and functioning institutions. The section which follows will provide an overview of the relevant theoretical foundations of the constructs under study. The section on methodology will detail the sampling and instrument design and indicate how the hypotheses are tested using structural equation modeling (SEM). Researchers note that an essential part of SEM analyses is "goodness of fit testing" (Fornell \& Larcker, 1981) which involves fitting SEM models and covariance structure modeling. Results and discussion follow, while the last section provides conclusions, considers repercussions for theory and policy, and examines limitations and future research directions. 


\section{Literature Review}

Entrepreneurial Orientation: Research shows that entrepreneurship may serve as a foundation for a strategy where firms who dedicate considerable resources to the innovation process, are able to obtain a competitive advantage (Dess and Lumpkin, 2005; Urban, 2016). A steady stream of research highlights the concept of EO as encompassing "organizational processes, practices and decision-making styles of innovative firms" (Covin and Lumpkin, 2011). Widespread research confirms that EO is best understood as a multidimensional construct and includes: innovativeness, risk-taking, and proactiveness (Dess and Lumpkin, 2005). Innovativeness is conceptualized in terms of uniqueness and emergent new products, services or processes. Risk-taking is related to managerial readiness to dedicate substantial resources to leverage new opportunities by way of taking and encouraging calculated risk-taking. Proactiveness is a resolution in implementing initiatives and involves fostering a culture of adaptability, experimenting and the acceptance of failure. Research reports that the extent to which each of these dimensions is valuable for forecasting the firm performance is largely dependent on the environment in which the firm operates in (Covin and Lumpkin, 2011; Dess and Lumpkin, 2005; Rauch et al., 2009). Research finding on EO, which incorporates these dimensions generally find that higher levels of EO are associated with success, even when firms are operating in hostile environments. Consequently, there have been calls to study EO from "a contingency perspective in terms of how environmental, organizational and individual factors, may moderate, mediate or interact with EO to enhance firm performance" (Anderson et al., 2009; Dess and Lumpkin, 2005; Rauch et al., 2009).

Entrepreneurial Alertness: Alertness and motives explain entrepreneurial recognition of opportunities, and affect start-up decisions and enterprise performance (Busenitz \& Lau 1996; Kirzner, 1997; Kruger, 2007; Urban, 2007). Research reveals that the successful performance of entrepreneurs is reliant on motivation and behavior where various models and theories (e.g., Shane et al., 2003) explain how both the nature of the individual and how they perceive the opportunity are important (Shane \& Venkataraman, 2000). Several studies have indicated how an individual's orientation or alertness is crucial to encouraging entrepreneurial growth and development (Davidsson \& Honig, 2003; Drnovsek \& Glas, 2002; Shane et al., 2003; Ucbasaran et al., 2001). Moreover, findings indicate that the ability to recognize opportunities is related to a variety of human and social capital variables such as level and application of education, type of work experience, as well as specific entrepreneurial knowledge and experience (Davidsson \& Honig, 2003; Ucbasaran et al., 2001). Research is also converging which reveals that the aptitude to recognize opportunities is primarily a cognitive function (Shane \& Venkataraman, 2000) where individuals are thought to hold unique cognitive scripts which allow them to have higher levels of alertness (Busenitz \& Lau 1996; Kirzner, 1997; Tang et al., 2012; Urban, 2016).

Based on several studies researchers' have recognized entrepreneurial alertness as best understood from a process perspective which consists of three stages, these are. The first phase, scanning and search represents persistently scanning the environment to ascertain information or changes which have occurred unobserved by some individuals; the second phase, association and connection is about assembling information and using that information as knowledge to develop alternatives or provide additional choices; the third phase, evaluation and judgment encompasses individuals making valuations and decisions about fluctuations and deciding whether these are in fact profitable opportunities (Tang et al., 2012). Recognizing that the abovementioned dimensions have been used in past studies to operationalize entrepreneurial alertness and for this study, the following hypothesis is formulated.

Hypothesis1: Entrepreneurial alertness as an individual level construct based on its constituent dimensions has a positive relationship with higher levels of firm entrepreneurial orientation.

Entrepreneurial Self-Efficacy: Entrepreneurial activity is often theorized to manifest as a result of numerous motivational and belief factors (Shane et al., 2003), where self-efficacy plays a pivotal role (Urban, 2007). Researchers consider motivation as an essential part of the entrepreneurial process which needs to be accompanied with concomitant individual level skills and capabilities. The construct of self-efficacy has been extensively interrogated in the field of behavioral management, where it is conceptualized as "people's 
judgments of their capabilities to organize and perform courses of action required to attain selected types of performance" (Bandura 1986, 1997). Findings across disciplines reveal that self-efficacy beliefs determine what trials the entrepreneur will accept and how long she will persist and continue under adverse conditions (Bandura, 1997; Urban, 2007). Research findings highlight that individuals are inclined to circumvent tasks about which they have low self-efficacy while, equally, are enticed to perform tasks about which they have a sense of high self-efficacy (Bandura, 1997; Earley, 1994). Self-efficacy has been applied to the entrepreneurship domain where the entrepreneurial self-efficacy (ESE) construct is used to designate "the strength of a person's belief that he or she is capable of successfully performing various roles and tasks of entrepreneur" (Chen et al., 1998; de Noble et al., 1999). ESE has been operationalized from the viewpoint of entrepreneurial tasks performed during the entrepreneurial process (McGee et al., 2009), where such a process perspective ensures that ESE may be measured across varying entrepreneurial activities. As past studies indicate that an individual's level of ESE may be related to higher levels of firm performance (Chen et al., 1998; de Noble et al., 1999), it is hypothesized that.

Hypothesis 2: Entrepreneurial self-efficacy (ESE) as an individual level construct based on its constituent dimensions has a positive relationship with entrepreneurial orientation.

Furthermore, by building on the principles of configuration theory, in particular, the SCT, which is premised on a combination or interaction of several characteristics (Andrevski et al., 2013, Bandura, 1986) the present study, recognizes that alertness and ESE may prove to be complementary. The rationale here is that entrepreneurs who are alert to opportunities may not engage because they lack self-belief and do not possess the requisite entrepreneurial capabilities (ESE) to carry out the various tasks required of an entrepreneur during the entrepreneurial process (Chen et al., 1998; De Noble et al., 1999). Consequently, the third hypothesis predicts an interaction in terms of alertness and ESE as:

Hypothesis 3: There is a positive interaction between entrepreneurial alertness and entrepreneurial selfefficacy (ESE).

Environmental Dynamism and Hostility: In the management literature, three characteristics have been used extensively to describe an industry's condition of the external environment, namely environmental hostility, dynamism and diversity (heterogeneity) (Dess \& Beard, 1984; Zahra \& Covin, 1995). These dimensions relate to two generally used approaches to theorizing about environments (Zahra \& Covin, 1995; Wright et al., 2015). The current study builds in this direction by relying on the dimensions of dynamism and hostility, as they are reliable with earlier theory and these two dimensions have in the past shown modest correlations [Zahra, 1993), which means that distinctive features of the environment are encapsulated with each dimension.

Dynamism points to the rate and unpredictability of change in the industry [Dess \& Beard, 1984]. Such changes may result from competitors' actions, developments in customer's' needs, and alterations in technological conditions. Such fluctuations create opportunities as well as threats for businesses and may force them to leverage innovations and other resources (Dess and Beard, 1984), as well as promote investments in new product development [Zahra \& Covin, 1995). Furthermore, studies indicate that entrepreneurial activities would be neglected without market changes and increased dynamism (Dess \& Beard, 1984). In principle the greater the market dynamism the greater the pressure for the firm to be more innovative (Wiklund et al., 2009; Zahra \& Covin, 1995).

On the other hand, hostility refers to an environment that is inherently risky and where few opportunities are available, often due to intense competition. Miller and Friesen (1982) describe hostility as the "degree of threat faced by the firm as a result of the intensity of the competition in the marketplace, as well as the vicissitudes of the industry". Hostility is expressed in terms of an overwhelming competitive environment, where the intensity of the competition is often accompanied by a dearth of opportunities. Researchers find that competitive intensity positively influences the SMEs open innovations, with findings revealing that the 
majority of innovations in technology are in response to competitive, hostile market pressures (Miller \& Friesen, 1982; Wright et al., 2015; Zahra \& Coven, 1995).

Hypothesis 4a: Perceived environmental dynamism and hostility mediate the relationship between entrepreneurial alertness and entrepreneurial orientation in such a manner that the association is positive and significant In line with configuration theories where a combination of several organizational attributes is theorized to have a greater influence on firm outcomes than the individual effects alone (Andrevski et al., 2013), the last hypotheses builds on the notion that individual level variables cannot be viewed in isolation but rather as a set of interrelated factors, where the environment also needs to give proper consideration (Urban, 2007). Subsequently it is predicted that individuals with more pronounced ESE perceive their business context as having more opportunities to exploit (Chen et al., 1998). Accordingly, the more hostile the environment, the higher the need for innovation and more likely SMEs will be entrepreneurial (Myers \& Marquis, 1969). Following this line of reasoning it is hypothesized that:

Hypothesis 4b: Perceived environmental dynamism and hostility mediate the relationship between selfefficacy (ESE) and entrepreneurial orientation in such a manner that the association is positive and significant.

\section{Research Methodology}

Sampling and Data Collection: The target population was based on sampling frames sourced from the South African National Small Business Chamber (NSBC, 2016), Business Partners (2016), and the Department of Trade and Industry (Dti, 2016). The study took place in the Gauteng region in South Africa (SA) which is the largest province in South Africa (SA) (Stats SA, 2014). SMEs were nominated in accord with the conventional method of describing SMEs in SA, which is in line with the Schedule of the National Small Business Amendment Act No. 29 (RSA, 2003). The selection criterion reflects various established limits for each sector or subsector as per the standard industrial classification (SIC). For the target population the sampling selection criteria are based on Total Full-time Equivalent (FTE) of paid employees is classified as Medium = 200 employees, and Small $=50$ employees (RSA, 2003). Furthermore, the SMEs had to "represent by ownermanagers who currently own and manage their enterprise/business" (Xavier et al., 2012). The reason being that owner-managers are typically well placed with regard to overseeing the planned endeavors of the whole enterprise (Venkataraman, 1997).

These sample selection criteria, also acted as the SME sample parameters or control variables which incorporated the size of the enterprise and age of the enterprise. The age of the enterprise (years of operation since the SME was created), and enterprise size were included in the model as prior studies have found these variables to be significant (Autio \& Acs, 2007). Following the identification of the different sampling frames, a well-established formula was used to determine the maximum sample size [Sheehan \& McMillan, 1999], where $s$ was the required sample size; $X^{2}$ was the table value of chi-square (1 degree of freedom and at the desired confidence level (3.541); $N$ was simply the population size; and $P$ the proportion of SMEs with $d$ expressed as the degree of accuracy expressed as a proportion (.05). Following the calculation, the results indicated a sample size of 300 as suitable. Several SMEs with incomplete firm information were discarded and a sampling frame of 1800 SME owner-managers were requested to complete the online survey contacted as per the given selection criteria. After numerous requests and reminders during a three-week period a total of 310responses were obtained (17.2\% response rate), which was judged adequate for the online survey (Sheehan \& McMillan, 1999). The characteristics of the sample revealed that the majority of the respondents were between the ages of 35 and 44 years old (73\%), male $(60 \%)$ and had attained a tertiary degree or diploma (67\%). Most of the enterprises were less than 15 years old (64\%), and relatively evenly distributed in terms of small-size (52\%) and medium-sized enterprises (48\%). To test for sampling bias, differences between early and late respondents in terms of firm age showed no statistically significant results $(\mathrm{t}$-test $=\mathrm{p}>$ $0.10)$.

Instruments: Independent variables (IVs): Entrepreneurial alertness (EA) was operationalized as per the 
theoretical overview where different dimensions best describe this process as per Tang et al. (2012). These dimensions are in turn "reflective constructs based on the respondent perceptions" in terms of: (1) scanning and search (4 items), (2) association and connection (5 items), and (3) evaluation and judgment (5 items). Sample items included "I have frequent interactions with others to acquire new information'; 'I see links between seemingly unrelated pieces of information'; 'I can distinguish between profitable opportunities and not-so-profitable opportunities". All items were measured with five-point Likert scales ranging from strongly agree (5) to strongly disagree (1). Entrepreneurial self-efficacy (ESE) was operationalized in terms of the empirical evidence on the various entrepreneurial tasks that entrepreneurs typically employ to navigate the entrepreneurial process and include functions such as "marketing, innovation, management, risk-taking, and financial control". The items for the self-efficacy assessment are based on Chen et al.'s (1998) ESE sub-scales (marginally modified) and consisted of items such as "I am good at developing new business ideas' and 'I can reduce risk and deal with uncertainty". The respondents indicating degree of certainty (high $=5$, low $=1$ ). In performing each of these roles/tasks on a 5-point Likert-type scale for the environment (ENV), the dimensions of hostility and dynamism were selected to reflect environmental perceptions [Zahra, 1993]. Environmental hostility was operationalized as "an adverse business climate, such as the powerful competition for various resources". Environmental dynamism was operationalized as "both the rate and unpredictability of change in a specific industry" (Dess \& Beard, 1984; Zahra \& Covin, 1995). Environmental dynamism (5-items) and hostility (6-items) were measured using a 7-point scale, representing ' $1=$ if you strongly agree and 7 = if you strongly disagree'. Recognizing that environmental perceptions may change depending on industry context, respondents were requested "to indicate the extent to which they agreed or disagreed with each statement as it applies to their principal industry in which they operate in".

Dependent variables (DV): Entrepreneurial orientation (EO) was operationalized using existing conceptualizations of EO, as it incorporates the three dimensions of innovation, risk-taking and proactiveness. Employing the multidimensional nature of EO is advantageous as it is backed by "theoretically meaningful relationships established in earlier studies, thus allowing for more advanced knowledge to evolve" (Dess and Lumpkin, 2005; Rauch et al., 2009). Consequently, EO was measured along a six-point bipolar Likert scale, represented by nine items. Respondents had to circle number " 1 if the statement on the left-hand side of the scale best designates your reaction to the item, or circle number 6 if the statement on your right-hand side of the scale best describes your reaction to the item".

Data Analysis: Literature provides different options on methods of configuration analysis, which include two-way and three-way interactions; cluster analysis, deviation scores and a set-theoretic approach. In particular, multiplicative three-way interactions are suitably used in testing for the effect of configurations consisting of three theoretical constructs (Andrevski et al., 2013), as is the case in the current study in terms of the hypothesized relationships between the constructs. Considering the nature of data collected, all from the same source, the study was vulnerable to common-method bias, which "affects item reliability and validity and/or the co-variation between two constructs" (Podsakoff et al., 2012). As recommended a number of "procedural and statistical steps were taken to offset these risks". First, all questions were required to be answered anonymously, and the questionnaires were returned directly to the researcher thus moderating any need for respondents' social desirability bias (Crowne \& Marlowe, 1960).

Second, existing scales were adapted and piloted $(n=25)$ to ensure that the scale items were clear and unambiguous to respondents. Third, the physical proximity between the dependent (DV) and independent variables (IVs) on the questionnaire was reduced. Lastly, the adoption of different scale anchors for different variables assisted in overcoming common methods bias (Podsakoff et al., 2012). This practice is also consistent with SEM applications, which can accept scales of any metric range including ratio type of measures with true zeros and has no upper limits (Hair et al., 2010). SEM was used because it incorporates measurement error in the estimation of the dependence relationships (Hair et al., 2010). Furthermore, as recommended in order examine the interrelationships between the study latent variables structural models must be generated using the maximum likelihood method of estimation (ML). 


\section{Results and Discussion}

Reliability and Validity Test Results: An exploratory factor analysis (EFA) was first applied to ensure that the constructs have convergent validity. Factors with Eigenvalues $>1$ were retained and factor loadings ranged between .69 and .92. This was followed by confirmatory factor analysis (CFA) to ensure that the items which did not meet pre-defined cut-off criteria ("with indicator loadings $\geq .4$; factor reliability (FR) $\geq .6$ and average variance extracted (AVE) $\geq .5$ ") were removed (Fornell \& Larcker, 1981). Initially the fit of each factor (subscale) and its observed items was assessed individually to determine whether there were any weak items with squared factor loadings below .20. Secondly, each factor or subscale was modelled together with other factors measuring the same theoretical construct to determine if convergent validity is achieved (first-order CFA model).

Results showed model fit estimates for each factor as a good model fit, with AVE $\geq .5$, indicating convergent validity among the dimensions. Thirdly, a second-order $\mathrm{CFA}^{1}$ model was tested in which the first-order factors became the indicators and finally CFA was run for the hypothesized model combining all theoretical constructs and their indicators to determine whether discriminate validity had been realized. That model estimates are presented in Table 1 which shows a chi-square value of $285.44(p=.000)$ and model fit indices such as nor medX $^{2}\left(\mathrm{X}^{2} / \mathrm{DF}\right)=2.23, \mathrm{GFI}=.91$, AGFI $=.87$, TLI $=.92$ and RMSEA $=.06$ indicating an acceptable model fit. Where necessary, improvements in the measurement model were made based on modification indices that indicated changes and standardized residual values. To improve model parsimony, variables with residual values greater than 1.96, low factor loadings and squared factor loadings below .20 were deleted incrementally (Hair et al., 2010). Scale reliability was tested by calculating Cronbach's alpha and item-to-total correlations, with satisfactory results (Nunnally, 1978) obtained in terms of: $\mathrm{ESE}=0.79$; $\mathrm{EA}=0.95$, ENV= $0.72 ; \mathrm{EO}=0.81$.

Descriptive and Correlations: Table 2 shows means, standard deviations and inter-correlations of the study variables. On the varying scale ranges the results indicate that ESE, EA and ENV are all above mid-point average while the mean scores for EO show lower mid-point averages. Pearson correlation coefficients indicate that several constructs are significantly correlated but not greater than 0.7 , an observation which is relevant in that it highlights that they are not too strongly correlated so as to cause multi Collin (Hair et al., 2010).

Table 1: Statistics for the Hypothesized Measurement Model

\begin{tabular}{|c|c|c|c|c|c|c|c|c|c|}
\hline Model Fit & & DF & $\mathrm{x}^{2}$ & $\mathrm{x}^{2} / \mathrm{DF}$ & $\mathbf{P}$ & GFI & AGFI & TLI & RMSEA \\
\hline Overall & & 128 & 285.44 & 2.23 & .000 & .92 & .85 & .90 & .06 \\
\hline Path & & & B & S.E. & C.R. & B & $\mathrm{L}^{2}$ & $\mathrm{P}$ & \\
\hline MKT & $<---$ & ESE & 1.00 & & & .77 & .55 & & \\
\hline INN & $<---$ & ESE & .62 & .08 & 6.88 & .42 & .18 & $* * *$ & \\
\hline MNGT & $<---$ & ESE & .15 & .05 & 3.92 & .23 & .06 & $* * *$ & \\
\hline RTC & $<---$ & ESE & .68 & .08 & 9.09 & .57 & .36 & $* * *$ & \\
\hline SCAN & $<---$ & EA & 1.00 & & & .71 & .54 & & \\
\hline ASSOC & $<---$ & EA & .75 & .08 & 11.10 & .71 & .55 & $* * *$ & \\
\hline EVAL & $<---$ & EA & 1.00 & .09 & 11.40 & .73 & .62 & $* * *$ & \\
\hline CHNG & $<---$ & ENV & 1.00 & & & .82 & .71 & & \\
\hline INV & $<---$ & EO & 1.00 & & & .73 & .57 & & \\
\hline RISK & $<---$ & EO & 1.05 & .09 & 12.65 & .74 & .56 & $* * *$ & \\
\hline PROAC & $<---$ & EO & 1.18 & .09 & 15.02 & .86 & .78 & $* * *$ & \\
\hline
\end{tabular}

\footnotetext{
1“The measurement models were tested for overall goodness of fit using Chi-Square but due to its sensitive to sample size and lack of a defined power function (Fornell \& Larker, 1981), other model fit tests included: the normed $x^{2}$, which is the ratio of chi-square and its degrees of freedom $\left(x^{2} / D F\right)$, goodness of fit index (GFI), adjusted goodness of fit index (AGFI), normal fit index (NFI), non-normal fit index (NNFI) or the Tucker-Lewis Index (TLI), comparative fit index (CFI), increment fit index (IFI), and root mean square error approximation (RMSEA)" (Fornell \& Larcker, 1981).
} 
*** Correlation is significant at .001 Levels (1-tailed), Abbreviations for factors and their sub-dimensions: "ESE = Entrepreneurial self-efficacy, MKT = Marketing, INN = Innovation, MNGT = Management, RTFC = Risktaking control; $\mathrm{EA}=$ Entrepreneurial alertness, SCAN $=$ Scanning and search, ASSOC = Association and connection, $\mathrm{EVAL}=$ Evaluation and judgment; $\mathrm{ENV}=$ Environmental dynamism and hostility; $\mathrm{EO}=$ Entrepreneurial orientation, INV = Innovation, RISK = Risk-taking, PROAC= Pro activeness".

Table 2: Descriptive and Correlation Matrix

\begin{tabular}{lllllll}
\hline Variable & EA & ESE & ENV & EO & Age & Size \\
\hline EA & 1 & & & & & \\
ESE & $.532^{* *}$ & 1 & & & & \\
ENV & $.512^{* *}$ & $.541^{* *}$ & 1 & & & \\
EO & $.371^{* *}$ & $.307^{* *}$ & $.398^{* *}$ & 1 & & \\
Age & $.222^{* *}$ & $.268^{* *}$ & .103 & .107 & 1 & 1 \\
Size & $.118^{* *}$ & $.243^{* *}$ & .121 & .155 & .017 & 0.19 \\
Mean & 4.19 & 4.32 & 3.88 & 2.76 & 0.05 & 0.79 \\
Std. dev. & 0.95 & 1.01 & 0.98 & 0.96 & 0.75 & \\
\hline
\end{tabular}

Hypotheses Test Results and Discussion: The hypothesized measurement model were tested as partially mediated and interaction effect models as per $\mathrm{H} 1$ and $\mathrm{H} 2$ which estimated direct effects while $\mathrm{H} 3$ estimated interaction effects and $\mathrm{H} 4$ and $\mathrm{H} 5$ mediation and interaction effects. Figure 1 shows the results for the full and partially mediated model which generated a chi-square of $2.36(\mathrm{p}=.308), \mathrm{RMR}=.01, \mathrm{GFI}=1.00, \mathrm{AGFI}=.97$, $\mathrm{CFI}=1.00, \mathrm{TLI}=.99$ and RMSEA $=.01$, indicating a very good and acceptable model (see Table 3 ). The full and partial interaction model in Figure 2 generated a chi-square of $2.45(\mathrm{p}=.311)$, GFI= 1.00, AGFI= .97, CFI= 1.00 , TLI .99 and RMSEA $=.02$ also revealing very good model fit (see Table 3 ). Thus, no modifications to the hypothesized partially mediated and interaction models were conducted because of the solid model fits obtained. The standardized parameter estimates for these models show several significant $(p<.01)$ values where both the direct and indirect path coefficients are displayed in Table 3 . The direct and indirect path coefficients indicate overall goodness of fit improvement, where the models account for variance in both ENV and EO. The path coefficients for the full mediation model in terms of ESE to ENV $(\beta=.224, p \leq .01)$, EA to EO $(\beta=.16, p>.01)$ and ESE to EO $(\beta=-.17, p \leq .01)$, are highest and provide support for H1-H4.

The ability of the partially mediated model to account for the variance in the criterion variable $\left(\mathrm{R}^{2}=.22\right)$ is fairer compared to $\left(\mathrm{R}^{2}=.04\right)$ in the fully mediated model. There is also a large difference between the models in terms of the partially and the fully mediated models as measured by PNFI. Comparison of the CFI values reveals that the partially mediated model is a better depiction of the relationships among the study variables. However, in comparing the two models, the $\mathrm{X}^{2}$ and CFI differences are not applicable since both models have good model fits. Hence, the two models are compared on PNFI and $\mathrm{R}^{2}$ change. The comparison of the full and partial interaction models reveals that the partial interaction model has a greater power to explain the variance in the dependent variable $\left(\mathrm{R}^{2}=.24\right)$ than the full interaction effect $\left(\mathrm{R}^{2}=.05\right)$.

In addition, the PNFI difference between the two models confirms that the partially interacted model is a more parsimonious model. Therefore, the partially mediated Model Figure 1 and partially interacted model Figure 2 are adopted in drawing conclusions and recommendations on the hypothesized effects where H1, H2 and $\mathrm{H} 3$ are supported. Overall, the partially mediated model accounts for 15 percent of the variance in the ENV and 22 percent of the variance in EO (see Table 3). This means that the ENV has the greatest effect on EO, providing support for $\mathrm{H} 4$ and $\mathrm{H} 5$. 


\section{Figure 1: Partial Mediation Effects Model}

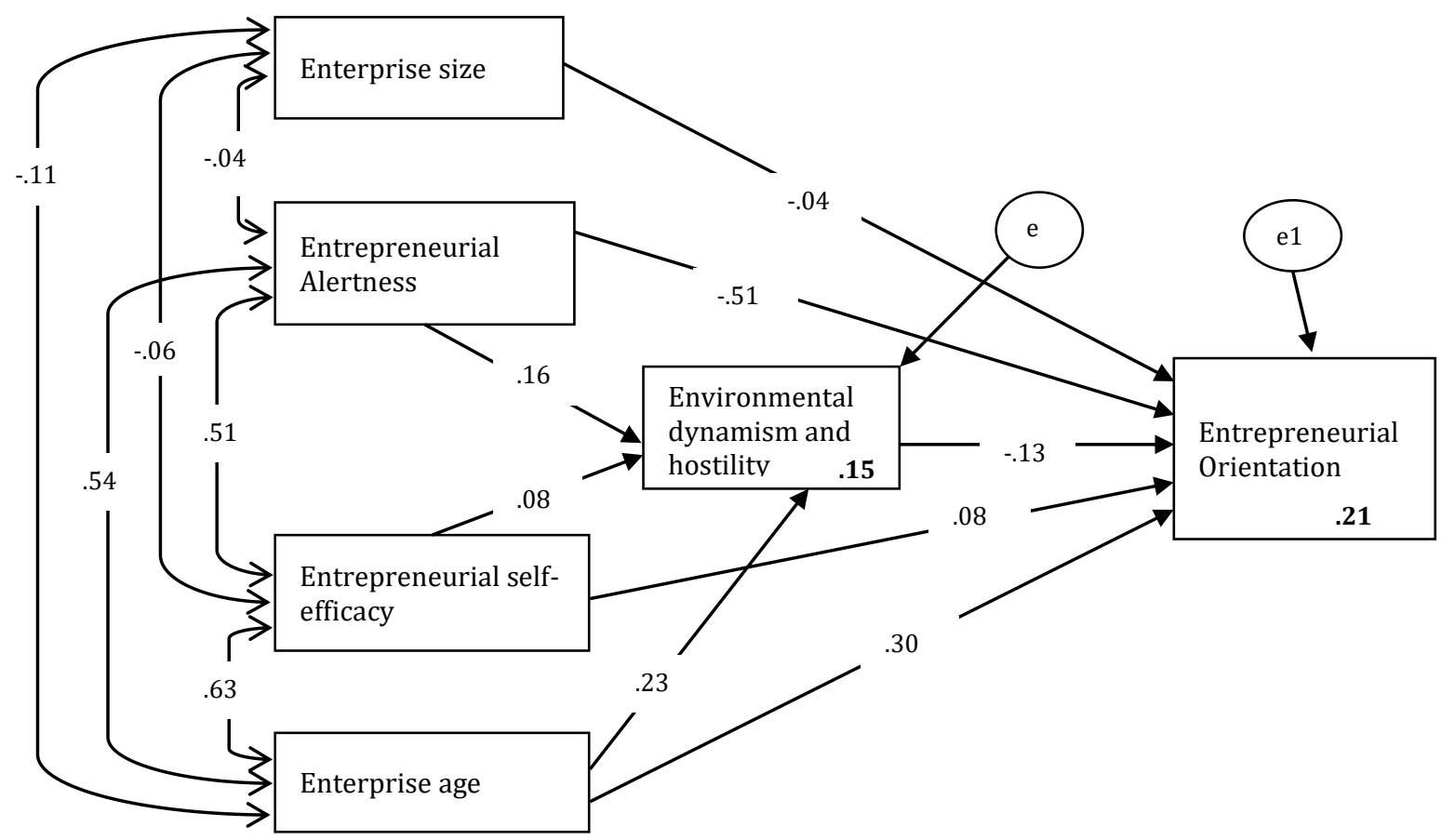

These results resonate with earlier studies where both environmental perceptions and the alertness and ESE of the individual are important determinants of entrepreneurship. The study has brought attention to the fact that environmental perceptions interact with individual-level variables to increase EO. These results coincide with similar studies which indicate that ESE influences levels of innovation and performance. Higher levels of ESE indicate that the entrepreneur has adopted greater competencies or expertise in entrepreneurial-related tasks such as risk-taking and innovation which translates into higher EO levels. Moreover, as entrepreneurs are motivated to innovate in areas which they have some expertise, capabilities and experience these influences are important to alertness (Autio \& Acs, 2007). Following the validation of the EO construct in this study it seems that EO is influenced positively by individual factors and forces operating within the broader environment in South Africa. Testing for the non-spurious relationship between constructs was done by comparing two structural models. The rule is that significance of the estimated relationships between the constructs in the two models should not be significantly different (Hair et al., 2010). On comparing the estimates for the two models as presented in Table 4, the significance of the structural relationships in terms of the constructs in model 1 remained unchanged when the control variables were added in the second model. In addition, the effect of control variables remained non-significant. This implies that the main effects as expected are not significantly affected by the size and age of the enterprise. Therefore, it can be assumed that the relationships as hypothesis in terms of the different constructs in the model were non-spurious and represented a true state of reality.

Such reasoning highlights the importance of the environmental context to innovation and EO were not only does the level and nature of entrepreneurship differ depending on the environment, but the differing types of entrepreneurial activity and their contribution to the economic development are reliant on the contextual conditions (Urban, 2007). In South Africa, despite policymakers having targeted entrepreneurial activity as an important element of the country's economic growth objectives, currently in the South African context innovation levels are declining where there has been a marked drop in entrepreneurs who believe they offer innovative products, (Herrington et al., 2017). The importance to have evidence-based policies that are fit for purpose is important when considering a lack of innovation and EO in many SMEs in emerging economies, such as South Africa. 


\section{Figure 2: Full Interaction Effects Model}

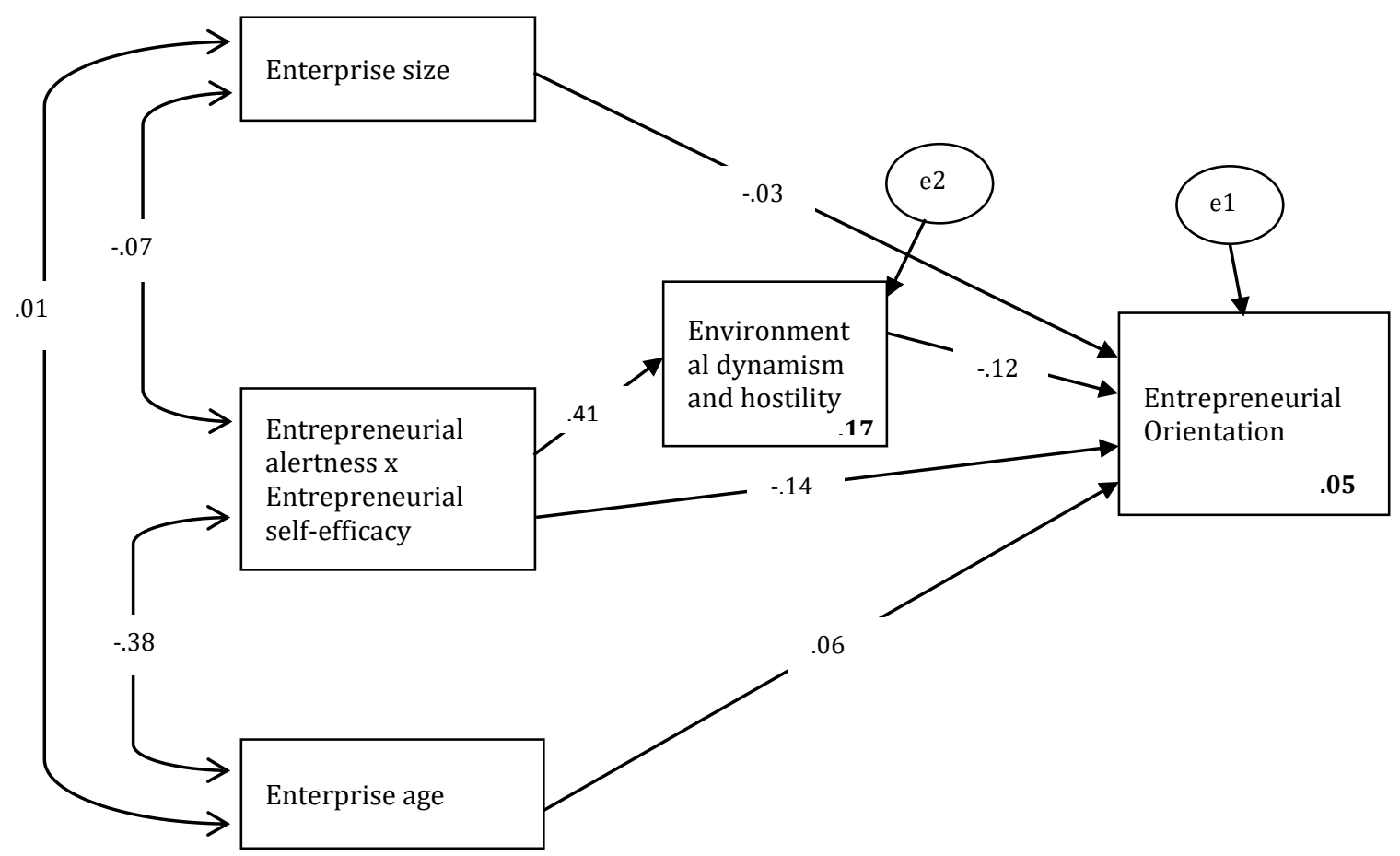

The extent of the combined effect of the predictor variables on ENV and EO was investigated through testing of hypotheses $\mathrm{H} 3$ and $\mathrm{H} 4$ in a multiplicative structural model of the predictor variables. The results indicate that a unit change in the multiplicative factor causes 0.76 unit increase in ENV. This means that the joint effect of the predictor variables causes an improvement in ENV and a reduction in EO. Overall, the partially interacted model accounts for 17 percent of the variance in ENV and 23 percent of the variance in EO see Figures 1 and 2. In addition, the relative effect of the interaction between the independent variables was observed. As shown in Table 5, the inclusion of the interaction term (EA*ESE) maximized the total positive effect of ENV and EO. On the other hand, however, the interaction term caused a negative total effect of individual independent variables on ENV which demonstrates the importance of direct and interaction effects of the independent variables on ENV and EO respectively. Another plausible explanation for the support of the study hypotheses is that while the environment may be characterized by hostility, change and dynamism, entrepreneurs still need to predict future scenarios and develop their alertness and ESE to effect higher levels of EO in such hostile surroundings (Dess and Lumpkin, 2005; Rauch et al., 2009).

The findings further resonate with past research, which suggests that the more dynamism and hostility is present in the environment, a greater need for innovation is more likely, and consequently firms will display higher levels of EO. In this sense, the study findings are in line with empirical evidence which suggests that in emerging and developing countries entrepreneurial activity is flourishing ahead of developed countries as opportunities are opening up in these markets (Xavier et al., 2012), with corresponding higher levels of EO. Notwithstanding the positive results obtained for the predicted relationships, a relatively modest role for the dynamic and hostile environment $\left(\mathrm{R}^{2}=.04\right)$ was observed in the fully mediated model. A plausible interpretation may be that dominant firms in the South African business environment entrench their market power and eventually push competitors out by relying on exclusionary practices, such as high barriers to entry. These competitor actions and tactics negatively influence how smaller enterprises deal with gaining vital inputs for their products, manage their cash flows and also affect their ability to access channels for distribution, which ultimately forces this business out of the marketplace (Kampel, 2003). 


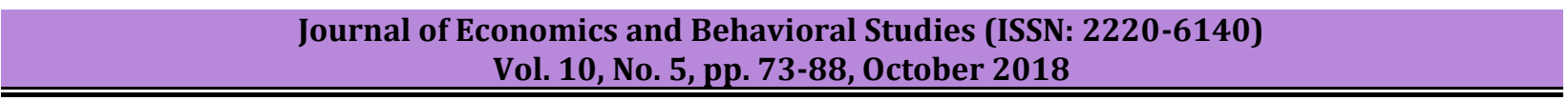

Table 3: Comparative Statistics for the Partially Mediation and Full Interaction Effects Models

\begin{tabular}{|c|c|c|c|c|c|c|}
\hline \multirow{2}{*}{\multicolumn{3}{|c|}{ Model Fit Index }} & \multirow{2}{*}{$\begin{array}{l}\text { Mediation } \\
\text { Full }\end{array}$} & \multicolumn{3}{|c|}{ Interaction } \\
\hline & & & & Partial & Full & Partial \\
\hline \multicolumn{3}{|l|}{$\mathrm{x} 2$} & 72.18 & 2.36 & 2.45 & 2.12 \\
\hline \multicolumn{3}{|l|}{ DF } & 8 & 2 & 2 & 2.00 \\
\hline \multicolumn{3}{|l|}{$\mathrm{P}$} & .000 & .31 & .31 & .35 \\
\hline \multicolumn{3}{|l|}{$\mathrm{X} 2 / \mathrm{DF}$} & 9.02 & 1.18 & 1.16 & 1.06 \\
\hline \multicolumn{3}{|l|}{ RMR } & .04 & .01 & .01 & .007 \\
\hline \multicolumn{3}{|l|}{ GFI } & .96 & 1.00 & 1.00 & 1.00 \\
\hline \multicolumn{3}{|l|}{ AGFI } & .72 & .97 & .97 & .97 \\
\hline \multicolumn{3}{|l|}{ NFI } & .86 & 1.00 & .92 & 1.00 \\
\hline \multicolumn{3}{|l|}{ RFI } & .21 & .95 & .8 & .98 \\
\hline \multicolumn{3}{|l|}{ IFI } & .87 & 1.00 & 1.00 & 1.00 \\
\hline \multicolumn{3}{|l|}{ TLI } & .23 & .99 & .97 & 1.00 \\
\hline \multicolumn{3}{|l|}{ CFI } & .86 & 1.00 & 1.00 & 1.00 \\
\hline \multicolumn{3}{|l|}{ RMSEA } & .16 & .02 & .02 & .01 \\
\hline \multicolumn{3}{|l|}{ PCLOSE } & .00 & .55 & .66 & .58 \\
\hline \multicolumn{3}{|l|}{ PNFI } & .15 & .1 & .194 & .07 \\
\hline \multicolumn{3}{|l|}{ PCFI } & .15 & .1 & .198 & .07 \\
\hline \multicolumn{3}{|l|}{ AIC } & $107 / 55$ & $53 / 55$ & $25 / 28$ & $71 / 73$ \\
\hline \multicolumn{3}{|l|}{ CAIC } & $214 / 183$ & $175 / 185$ & $89 / 100$ & $230 / 241$ \\
\hline \multicolumn{3}{|l|}{ ECVI } & $.324 / .186$ & $.177 / .182$ & $.093 / .099$ & $.231 / .238$ \\
\hline \multicolumn{3}{|l|}{ Hoelter $\mathrm{p}=.05$} & 56 & 775 & 753 & 846 \\
\hline \multicolumn{3}{|l|}{ Hoelter $\mathrm{p}=.01$} & 72 & 1009 & 1118 & 1216 \\
\hline \multicolumn{3}{|l|}{ Path } & B & $\boldsymbol{\beta}$ & B & B \\
\hline ENV & $<---$ & EA & .08 & .08 & & -.13 \\
\hline ENV & $<---$ & ESE & $.224^{* *}$ & $.23^{* *}$ & & -.12 \\
\hline EO & $<---$ & EA & $.16^{* *}$ & $.16^{* *}$ & & -.15 \\
\hline EO & $<---$ & ESE & $-.17^{* *}$ & $-.13^{*}$ & $-.12^{*}$ & $-.12^{*}$ \\
\hline EO & $<---$ & ENV & & .08 & & $.38^{* *}$ \\
\hline ENV & $<---$ & Size & -.06 & -.04 & 0.06 & -.03 \\
\hline ENV & $<---$ & Age & & $-.51^{* * *}$ & & -.06 \\
\hline EO & $<---$ & Size & & $.30 * * *$ & & $.79 * * *$ \\
\hline EO & $<---$ & Age & .06 & .06 & 0.02 & .06 \\
\hline ENV & $<---$ & $\mathrm{EA}^{*} \mathrm{ESE}$ & & & $.41^{* * *}$ & $.74^{* * *}$ \\
\hline EO & $<---$ & EA*ESE & & & $-.14^{*}$ & $-1.06^{* *}$ \\
\hline Variance Expla & & & $\mathbf{R}^{2}$ & $\mathbf{R}^{2}$ & $\mathbf{R}^{2}$ & $\mathbf{R}^{2}$ \\
\hline ENV & & & .15 & .16 & .17 & .17 \\
\hline EO & & & .04 & .22 & .05 & .24 \\
\hline
\end{tabular}


Table 4: Test Results for No Spurious Relationship between Constructs

\begin{tabular}{lllllcc}
\hline \multicolumn{1}{c}{ Path } & & & $\begin{array}{l}\text { Model 1 } \\
\text { Estimate }\end{array}$ & P-values & $\begin{array}{l}\text { Model 2 } \\
\text { Estimate }\end{array}$ & P-Values \\
\hline ENV & $<---$ & EA & .08 & .233 & .08 & .233 \\
ENV & $<---$ & Size & .22 & .002 & .22 & .002 \\
ENV & $<--$ & ESE & .16 & .011 & .16 & .011 \\
ENV & $<---$ & Age & $(.14)$ & .013 & $(.13)$ & .018 \\
EO & $<---$ & EA & .08 & .229 & .08 & .258 \\
EO & $<---$ & ESE & & & .04 & .450 \\
EO & $<---$ & Size & $.51)$ & $* * *$ & $.51)$ & $* * *$ \\
EO & $<---$ & Age & .28 & $* * *$ & .30 & $* * *$ \\
\hline
\end{tabular}

Table 5: Direct and Indirect Effects of the Interaction Model

\begin{tabular}{lllllll}
\hline Standardized Total Effects & EA & ESE & E1 & E2 & EA*ESE & ENV \\
\hline ENV & .12 & .14 & - & - & .74 & - \\
EO & .43 & .05 & .02 & .06 & 1.04 & .13 \\
Standardized Direct Effects & EA & ESE & B4 & B5 & EC*ESE & ENV \\
ENV & .12 & .16 & - & - & .64 & - \\
EO & .39 & .06 & -02 & .06 & -.05 & -.13 \\
Standardized Indirect Effects & EA & ESE & B4 & B5 & EC*ESE & ENV \\
ENV & - & - & - & - & - & - \\
EO & .02 & .02 & - & - & -.09 & - \\
\hline
\end{tabular}

Based on the extensive statistical analyses conducted, the study hypotheses are supported. Similar to other studies, the study findings reveal that behavioral and cognitive manifestations of alertness and self-efficacy lead to higher levels of EO (Urban, 2016). Recognizing the vital links between alertness, ESE and EO, this study makes a meaningful contribution by providing empirical evidence in terms of modelling these relationships. With developments in social psychology research (Luthans et al., 2000) this currently permits entrepreneurship researchers to tackle the "thinking-doing connection" more directly, by focusing on ESE and alertness. Such an approach is a more fruitful area of research, it could be argued, in contrast to using alternative variables such as demographics. With the advances being made in fields such social neuroscience it is important that scholars attempt to "understand how knowledge is structured at a very deep level" (Krueger, 2007), which is focused on discovering the entrepreneurial mindset in terms of on alertness and ESE.

Limitations and Future Research: The study has typical cross-sectional design shortcomings as the paper loses full understanding whether alertness and ESE may well change over time. In this regard longitudinal studies are essential to examine whether entrepreneurial alertness and ESE can persist under conditions of environmental dynamism and hostility. Since the study relied on perceptual data some responses could be considered prejudiced by biases and cognitive inadequacies. Furthermore, as with previous studies, using cumulative measures of environmental perceptions may obscure less researched effects (Welter \& Small bone, 2011), such as cultural traditions and the power of informal political institutions such as party politics on EO.

\section{Conclusion}

An important conclusion of this study is that the relationships between entrepreneurial alertness, selfefficacy and entrepreneurial orientation are mediated by environmental dynamism and hostility. The study adds to the growing literature on entrepreneurship by showing how interactions between these variables provide a more understandable and academically rigorous on figuration than any of the study factors would display if studied in isolation. The study also extends the current research agenda which notes that the 
interconnectedness of exogenous environmental processes in an emerging market, such as South Africa make it problematic to isolate unique factors as determinants of entrepreneurship (Urban, 2016).

Implications: The study findings can be advanced to practice and education, where consideration of alertness and self-efficacy as skills and abilities to be mastered could be brought into the design of curriculum and teaching methodologies, which can improve learning and instigate innovation. Considering the environmental dynamism and hostility facing entrepreneurs, they will need to develop higher levels of alertness and ESE to effectively deal with the complexity and changes present in the business environment (Baron, 2006; Gaglio \& Katz, 2001). The study findings also have relevance at more national global levels where research indicates that significant job creation and firm performance result from disruptive and innovative opportunities, as opposed to self-employment opportunities', which are rarely scalable and mostly necessity based in emerging economies (Alvarez \& Barney, 2014).

Recommendations: Policy is often used as an institutional mechanism to act as an enabler for enterprise start-ups and growth. It is recommended that policy should address the EO of SMEs by focusing on alertness, ESE and environmental perceptions. Policymakers can encourage entrepreneurship by fostering higher levels of alertness and ESE to alleviate some of the effects of hostile environments. As literature reveals, it is often the differences in perceptions which results in distinctions in opportunities pursued by the entrepreneur. An entrepreneur who is alert and has high levels of ESE may recognize one particular type of opportunity, whereas others may not even be aware that the opportunity exists (Autio \& Acs, 2007; Venkataraman, 1997). In terms of academic relevance, this study contributes to the innovation and entrepreneurship literature, which has largely neglected understanding the impact that cognitive and behavioral perceptions have on EO in an emerging market context. Future studies could focus on different country institutional environmental conditions and determine if alertness and ESE are influenced positively by these institutions when pursuing EO. In general, developing a greater awareness of the complexities of the individual and the environment represents a productive area for future research.

\section{References}

Alvarez, S. A., Barney, J. B. (2014). Entrepreneurial opportunities and poverty alleviation. Entrepreneurship Theory and Practice, 38(1), 159-184.

Anderson, B. S., Covin, J. G. \& Slevin, D. P. (2009). Understanding the relationship between entrepreneurial orientation and strategic learning capability: an empirical investigation. Strategic Entrepreneurship Journal, 3(3), 218-240.

Andrevski, G., Brass, D. J. \& Ferrier, W. J. (2013). Alliance portfolio configurations and competitive action frequency. Journal of Management, 20(10), 1-27.

Ardichvili, A, Cardozo, R. \& Ray, S. (2003). A theory of entrepreneurial opportunity identification and development. Journal of Business Venturing, 18(1), 105-123.

Autio, E. \& Acs, Z. J. (2007). Individual and country-level determinants of growth aspiration in new ventures', in A. Zacharakis (Ed.). Frontiers of Entrepreneurship Research, 121-156.

Bamiatzi, V. C. \& Kirchmaier, T. (2012). Strategies for superior performance under adverse conditions: A focus on small and medium-sized high-growth firms. International Small Business Journal, 32(3), 259 -284.

Bandura, A. (1986). Social Foundations of Thought and Action: A Social Cognitive Theory. Englewood Cliffs, N.J.: Prentice-Hall.

Bandura, A. (1997). Self-efficacy: The Exercise of Control. New York: W.H. Freeman \& Company.

Baron, R. A. (2006). Opportunity recognition as pattern recognition: How entrepreneurs "connect the dots" to identify new business opportunities. Academy of Management Perspectives, 20, 104-119.

Basardien, F., Friedrich, C. \& Twum-Darko, M. (2016). Evidence-based practices of promoting entrepreneurship education in Higher Education institutions in Africa. Journal of Economics and Behavioral Studies, 8(5), 68-81.

Brownhilder, N. (2016). Examining the moderating effect of environmental hostility on the entrepreneurial orientation-performance relationship. Journal of Economics and Behavioral Studies, 8(6), 6-18. 
Bruwer, J. P. (2018). Do internal control activities adversely influence the profitability and solvency of South African SMMEs? Journal of Economics and Behavioral Studies, 10(1), 49-58.

Busenitz, L. W. \& Lau, C. M. (1996). A cross-cultural cognitive model of new venture creation. Entrepreneurship Theory and Practice, 20(1), 25-39.

Busenitz, L. W., Plummer, L. A., Klotz, A. C., Shahzad, A. \& Rhoads, K. (2014). Entrepreneurship research (1985-2009) and the emergence of opportunities. Entrepreneurship Theory and Practice, 38(8), 9811000.

Business Partners. (2016). Available at: https://www.businesspartners.co.za/en-za.

Chen, C. C., Greene, P. G. \& Crick, A. (1998). Does entrepreneurial self-efficacy distinguish entrepreneurs from managers? Journal of Business Venturing, 13(2), 295-316.

Covin, J. G. \& Lumpkin, G. (2011). Entrepreneurial orientation theory and research: reflections on a needed construct. Entrepreneurship Theory and Practice, 35(5), 855-872.

Crowne, D. \& Marlowe, D. (1960). A new scale of social desirability independent of psychopathology. Journal of Consulting Psychology, 24(4), 340-354.

Davidsson, P. \& Honig, B. (2003). The role of social and human capital among nascent entrepreneurs. Journal of Business Venturing, 18(3), 301-331.

Davidsson, P., Delmar, F. \& Wiklund, J. (2006). Entrepreneurship and the growth of firms. Cheltenham, UK: Edward Elgar.

De Noble, A. F., Jung, D. \& Ehrlich S. B. (1999). Entrepreneurial self-efficacy: The development of a measure and its relationship to entrepreneurial action. Frontiers of Entrepreneurship Research. Babson: Babson College.

Department of Trade and Industry. (2016). Available at: www.dti.gov.za.

Dess, G. G. \& Beard, D. W. (1984). Dimensions of organizational task environment. Administrative Staff Quarterly, 29(1), 52-73.

Dess, G. G. \& Lumpkin, G. T. (2005). The role of entrepreneurial orientation in stimulating effective corporate entrepreneurship. Academy of Management Perspectives, 19(1), 147-156.

Dobbs, M. \& Hamilton, R. T. (2007). Small business growth: recent evidence and new directions. International Journal of Entrepreneurial Behavior and Research, 13(5), 296-322.

Drnovsek, M. \& Glas, M. (2002). The entrepreneurial self-efficacy of nascent entrepreneurs: The case of two economies in transition. Journal of Enterprising Culture, 10(2), 107-131.

Earley, P. C. (1994). Self or group? Cultural effects of training on self-efficacy and performance. Administrative Science Quarterly, 39(1), 89-109.

Estrin, S., Korosteleva, J. \& Mickiwicz, T. (2013). Which institutions encourage entrepreneurial growth aspirations? Journal of Business Venturing, 28(1), 564-580.

Fornell, C. \& Larcker, D. F. (1981). Evaluating structural equation models with unobservable variables and measurement error. Journal of Marketing Research, 18(2), 39-50.

Gaglio, C. M. \& Katz, J. (2001). The psychological basis of opportunity identification: entrepreneurial alertness. Journal of Small Business Economics, 16(1), 95-111.

Hair J. F., Black W. C., Babin B. J. \& Anderson R. E. (2010). Multivariate data analysis: a global perspective. (Eds.). 7th Ed, Upper Saddle River, NJ: Pearson.

Hameed, I. \& Ali, B. (2011). Impact of entrepreneurial orientation, entrepreneurial management and environmental dynamism on firm's financial performance. Journal of Economics and Behavioral Studies, 3(2), 101-114.

Haynie, J. M., Shepherd, D., Mosakowski, E. \& Earley, P. C. (2010). A situated metacognitive model of the entrepreneurial mindset. Journal of Business Venturing, 25(2), 217-229.

Herrington, M., Kew, P. \& Mwanga, A. (2017). South Africa Report 2016/2017. Can Small Businesses Survive in South Africa? Cape Town: UCT.

Kaish, S., Gilad B. (1991). Characteristics of opportunity search for entrepreneurs versus executives: sources, interests, and general alertness. Journal of Business Venturing, 6(1), 45-61.

Kampel, K. (2003). The role of South African competition law in supporting SMEs. Paper presented at the 48th ICSB World Conference, Advancing Entrepreneurship and Small Business 15-18 June 2003, Belfast, Northern Ireland. 
Khanna, T. \& Palepu, K. G. (2010). Winning in emerging markets: A roadmap for strategy and execution. Boston: Harvard Business School Press.

Kirzner, I. M. (1997). Entrepreneurial discovery and the competitive market process: An Austrian approach. Review of Austrian Economics, 11(12), 5-17.

Krueger, N. F. (2007). What lies beneath? The experiential essence of entrepreneurial thinking. Entrepreneurship Theory and Practice, 31(1), 123-138.

Lundström, A. \& Stevenson, L. (2005). Entrepreneurship Policy: Theory and Practice, Volume 9, New York: Springer.

Luthans, F., Stajkovic, A. D. \& Ibrayeva, E. (2000). Environmental and psychological challenges facing entrepreneurial development in transitional economies. Journal of World Business, 35(1), 95-117.

McGee, J. E., Peterson, M., Mueller, S. L. \& Sequeira J. M. (2009). Entrepreneurial self-efficacy: refining the measure. Entrepreneurship Theory and Practice, 33(1), 1-24

McGrath, R. G., Macmillan, I. C. \& Scheinberg, S. (1992). Elitists, risk takers, and rugged individualists? An exploratory analysis of cultural differences between entrepreneurs and non-entrepreneurs. Journal of Business Venturing, 7(1), 115-135.

Miller, D. \& Friesen, P. H. (1982). Innovation in conservative and entrepreneurial firms: two models of strategic momentum. Strategic Management Journal, 3(1), 1-25.

Moroz, P. W. \& Hindle, K. (2012). Entrepreneurship as a process: Toward harmonizing multiple perspectives. Entrepreneurship Theory and Practice, 36(4), 781-818.

Myers, S. \& Marquis, D. G. (1969), Successful industrial innovation. Washington DC. National Science Foundation.

National Small Business Chamber (NSBC). (2016). Fueling Small Business Growth: National Small Business Chamber. Available from: https://www.nsbc.org.za.

Nunnally, J. C. (1978). Psychometric theory, (2nd Ed.). New York: McGraw-Hill.

Piispanen, V. V., Paloniemi, K. J. \& Simonen, J. (2018). Qualities of the growth-oriented entrepreneur. International Journal of Entrepreneurship and Small Business, 34 (1), 112 - 130.

Podsakoff, P. M., Mackenzie, S. B. \& Podsakoff, N. P. (2012). Sources of method bias in social science research and recommendations on how to control it. Annual Review of Psychology, 63(5), 539-569.

Poon, J. M. L. (2006). Effects of self-concept traits and entrepreneurial orientation on firm performance. International Small Business Journal, 24(1), 61-82.

Rauch, A., Wiklund, J., Lumpkin, G. \& Frese, M. (2009). Entrepreneurial orientation and business performance: an assessment of past research and suggestions for the future. Entrepreneurship Theory and Practice, 33(3), 761-787.

RSA, Republic of South Africa. (2003). National Small Business Act 102 of 1996. Cape Town: Government Printers.

Samson, A. T. \& Mahmood, R. (2015). The impact of entrepreneurial orientation, reconfiguring capability and moderation of environmental turbulence on export performance of SMEs in Nigeria. Journal of Economics and Behavioral Studies, 7(3), 76-87.

Shane, S. \& Venkataraman, S. (2000). The promise of entrepreneurship as a field of research. Academy of Management Review, 25(1), 217-226.

Shane, S., Locke, E. A. \& Collins, C. J. (2003). Entrepreneurial motivation. Human Resource Management Review, 13(2), 257-279.

Sheehan, K. B. \& McMillan, S. J. (1999). Response variation in e-mail surveys: An exploration. Journal of Advertising Research, 39(4), 45-54.

Statistics South Africa. (2014). Gross domestic product, Annual estimates 2004 - 2013, Regional estimates 2004 - 2013. Third quarter 2014. Statistical release P0441, Pretoria.

Tang, J. Kacmar, K. M. M. \& Busenitz, L. (2012). Entrepreneurial alertness in the pursuit of new opportunities. Journal of Business Venturing, 27(1), 77-94.

Ucbasaran, D., Westhead, P., Wright, M. (2001). The focus of entrepreneurial research: contextual and process issues. Entrepreneurship Theory and Practice, 25(1), 34-45.

Urban, B. \& Hwindingwi, R (2016). Institutional factors in African Emerging Markets influencing MNE corporate strategies. International Journal of Emerging Markets, 11(4), 497-513. 


\section{Journal of Economics and Behavioral Studies (ISSN: 2220-6140)}

Vol. 10, No. 5, pp. 73-88, October 2018

Urban, B. (2007). A framework for understanding the role of culture in entrepreneurship. Acta Commercii, $7(1), 82-95$.

Urban, B. (2016). Empirical evidence on the influence of the institutional environment on venture innovation performance in South Africa. Journal of Developmental Entrepreneurship, 21(2), 1-14.

Venkataraman, S. (1997). The distinctive domain of entrepreneurial research. Advances in Entrepreneurship. Firm Emergence and Growth, 3(1), 119-138.

Welter, F. \& Small bone, D. (2011). Institutional perspectives on entrepreneurial behavior in challenging environments. Journal of Small Business Management, 49(1), 107-125.

Wiklund, J., Patzelt, H. \& Shepherd, D. A. (2009). Building an integrative model of small business growth. Small Business Economics, 32(4), 351-375.

Wright, M., Roper, S., Hart, M. \& Carter, S. (2015). Joining the dots: Building the evidence base for SME growth policy. International Small Business Journal, 33(1), 3-11.

Xavier, S. R., Kelley, D., Kew, J., Herrington, M. \& Vorderwulbecke, A. (2012). Global Entrepreneurship Monitor 2012 Global Report. London: Global Entrepreneurship Research Association.

Zahra, S. (1993). A conceptual model of entrepreneurship as firm behavior: a critique and extension. Entrepreneurship Theory and Practice, 16(1), 5-21.

Zahra, S. A. \& Covin, J. G. (1995). Contextual influences on the corporate entrepreneurship-performance relationship: A longitudinal analysis. Journal of Business Venturing, 10(1), 43-58. 